\title{
Evaluation of Erosion-corrosion Resistance in Fe-Mn-Al Austenitic Steels
}

\author{
William Arnulfo Aperador ${ }^{\text {a* }}$, Jorge Hernando Bautista Ruiz ${ }^{\mathrm{b}}$, Juan D. Betancurt ${ }^{\mathrm{c}}$

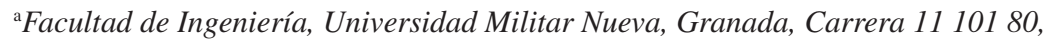 \\ ZIP code 110911, Bogotá, Colombia \\ ${ }^{\mathrm{b}}$ Facultad de ciencias, Universidad Francisco de Paula Santander, Avenida Gran Colombia No, 12E-96, \\ Barrio Colsag, ZIP code 540001, Cúcuta, Colombia \\ 'Programa de Integridad VIT, SNC-Lavalin Itansuca Proyectos de Ingeniería S. A. Cl 35 7-25 P-5, \\ ZIP code 110912, Bogotá, Colombia
}

Received: May 6, 2012; Revised: September 13, 2012

In this paper, the effects of $\mathrm{Mn}$ and $\mathrm{Al}$ against corrosion/errosion resistance of three samples of the Fe-Mn-Al austenitic alloys are evaluated. The samples have composition Fe-(4,9 11,0 wt. (\%)) Al-(17,49 34,3 wt. (\%)) Mn- $(0,43 \sim 1,25$ wt. $(\%))$ C, those were prepared in an induction furnace from high purity materials. The alloys were evaluated in a composed solution of $\mathrm{NaCl} 0,5 \mathrm{M}$ and Silica in a special chamber and AISI 316 stainless steel as reference material. The electrochemical characterization was performed by Tafel curve polarizations technique. This microstructural characterization was by Scanning Electron Microscopy (SEM). It was observed the significant decrease in the corrosion rate for steels Fermanal with a lower percentage of aluminum and manganese under conditions of dynamic corrosion and erosion-corrosion. SEM allows assessment of the dominant damage mechanisms and corroborated the results obtained by electrochemical measurements.

Keywords: corrosion, erosion, synergy, fermanal

\section{Introduction}

Fermanal steels are produced based on the ternary alloy $\mathrm{Fe}-\mathrm{Mn}-\mathrm{Al}$ and stainless steels are produced based on a ternary alloy Fe-Ni-Cr. These kinds of alloys show a great similarity, because both, the chrome and the aluminum form a thin oxide layer which protects the material from a future oxidation. Additionally, both the nickel and the manganese stabilize the austenitic phase. An advantage of fermanal steels is the lower cost and lower density in respect to the conventional steels ${ }^{1-5}$.

In 1987, Binczyk et al. ${ }^{6}$ made a study of the microstructure influence on the hardness of the fermanal steels. The microstructure was modified by heat treatments. Those treatments consisted of three stages, solubilisation, quenching and aging. This study concluded that the hardness of the fermanal steels increases with the aluminum content and decreases with the heat treatments, especially if the aging is performed at high temperatures $\left(600{ }^{\circ} \mathrm{C}\right.$ and $750^{\circ} \mathrm{C}$ ). The hardness increases since, the aluminum has an atomic radius bigger than the iron and the manganese ${ }^{7}$. This distortion will be higher if the content of aluminum is higher.

In most of items of industrial processes involves the contact with fluids of different nature, that's why exposed pieces to the action of these fluids may present corrosion process by erosion, reducing quickly its useful life. The corrosion by erosion is the acceleration in the rate of corrosion of a metal due to the relative motion of a corrosive fluid in contact with the metal surface ${ }^{8-10}$, if in addition the fluid present content of solid particles in suspension tends to increase the erosive effect causing deterioration of the metal.

*e-mail: g.ing.materiales@gmail.com
In wet corrosion has been found that the alloys $\mathrm{Fe}-\mathrm{Mn}-\mathrm{Al}$ have low corrosion resistance in various corrosive media $\left(\mathrm{HNO}_{3}, 5 \% \mathrm{H}_{2} \mathrm{SO}_{4}, \mathrm{FeCl}_{3} 10 \%\right.$ and $40 \%, 3 \% \mathrm{NaCl}$ and $50 \%$ acetic acid), which has limited their use in industrial applications ${ }^{2}$. For this reason, research has developed by Zhang et al. ${ }^{11,12}$ who have dedicated himself to the study of aqueous corrosion behavior of alloys with addition of dopants Fermanal as Cr. These dopants have a beneficial effect in these alloys. The aim of these researchers has been to provide the best addition to the composition of the alloy (Al-Cr). Establish the dopant and the amount that encourage the best behavior for passivation and other electrochemical parameters obtained during electrochemical measurements, such as fail to target to establish the mechanism of corrosion through knowledge of the corrosion products given environmental conditions, and to determine that these alloys can only be passivated in solutions of $10 \%$ to $50 \% \mathrm{Na}(\mathrm{OH})$ but not in solutions of $3.5 \% \mathrm{NaCl}$. As for the investigation of the alloys $\mathrm{Fe}-\mathrm{Mn}-\mathrm{Al}$ in terms of wear and erosion have few references in the literature, highlighting the research undertaken by Her-Hsiung Huang et al. ${ }^{13}$. In this research we studied the behavior of a Fe-Mn-Al solution heat treated and aged in a solution of $3 \% \mathrm{NaCl}$ aerated. In Colombia, the manufacturing industry, use tools or devices such the pumps which wear out and corrode rapidly due to the operating condition generating high economic costs. To prevent the damage to the components of the pumps, it has been chosen to create its parts with a wide range of materials as stainless steels, nickel, rubber and even the use 
of hard coating ${ }^{14-16}$, however, is important to evaluate new metallic materials, especially the fermanal steels. However, despite the important research developed, is not enough the literature information about the corrosion mechanisms and its behaviour in different aggressive media of this alloys series, while it has been tested widely in corrosion conditions under tension and high temperature oxidation ${ }^{7,11}$.

It is proposed with this investigation to study the electrochemical nature of the alloys Fe-Mn-Al (Fermanal) to analyse the chemical response in aggressive media, the erosion phenomenon and erosion-corrosion synergism. This study will allow collecting enough information of the elements $\mathrm{Mn}$ and $\mathrm{Al}$, in order to determine the influence of these two alloying elements.

\section{Experimental Details}

The chemical composition of the alloys studied in this work is shown in Table 1. These compositions were prepared from the high purity materials in an induction furnace. The samples were forged at $1100{ }^{\circ} \mathrm{C}$, then it was performed an homogenized sample at $1100^{\circ} \mathrm{C}$ for 11 hours and subsequently a laminated until $2.5 \mathrm{~mm}$ thick. The alloys were cut to the size of work in each case, with refrigeration by water, cutting machine and after to the annealing at $1100{ }^{\circ} \mathrm{C}$ for an hour in an argon tube furnace, subsequently quenching that will be performed at room temperature. Finally, they were cleaned by ultrasonically in an acetone bath and air dried before its use. Additionally, commercial austenitic stainless steel AISI 316L was used as a comparison.

The analysis of the total mass loss by erosion damage as a function of bilayer number was obtained by means of stopping the system at intervals of 10 minutes, with a total time of 2 hours for impact angle $90^{\circ}$. As for the analysis of the erosive, corrosive and erosive-corrosive effects, a device built for the evaluation of chemical attack in metallic materials was used. The erosive-corrosive testing device consists of a tribometer with a glass container for erosive-corrosive storage, one reference and one counter electrode, an acrylic cover that is available in the sample holder and electrodes, a impeller of High Ultra Molecular Weight Polyethylene (HUMWPE) which rests on the teflon shaft that is attached to the main motor shaft that provides fluid motion. The lid of the container allows locating two different samples exposed under angle for corrosive fluid action $\left(90^{\circ}\right)$. The fluid movement is caused by a shaft driver of the motor. The speed motor was fixed to 1930 RPM, the tangential speed applied to the fluid was fixed to $11.12 \mathrm{~m} / \mathrm{s}$.

The electrochemical study was carried out with a Gamry unit, model PCI 4 with D.C. signal which generates Tafel polarization curves. These curves were obtained at room temperature using a cell that supports one working electrode within an exposed area $\left(1 \mathrm{~cm}^{2}\right)$, a reference electrode $(\mathrm{Ag} / \mathrm{AgCl})$ and a graphite counter electrode in a $3.5 \%$ $\mathrm{NaCl}$ solution with distilled water. The resting potential was measured during 30 minutes to ensure repeatability of results. The Tafel curves were taken about 2.2 hours in the test, this time was necessary for the anodic and cathodic sweep potentials. Tafel polarization curves were obtained at a sweep speed of $0.125 \mathrm{mV} / \mathrm{s}$ within a voltage range from $-0.25 \mathrm{~V}$ to $0.75 \mathrm{~V}$ with an exposed area of $1 \mathrm{~cm}^{2}$.
The applied standards in the measurement criteria and the calculations correspond to the ASTM G5 and G59 ${ }^{[17,18]}$. In this work, silica $\left(\mathrm{SiO}_{2}\right)$ was used as an abrasive agent with a particle size between $210 \mu \mathrm{m}$ and $300 \mu \mathrm{m}$. This chemical solution was chosen since it has been shown that it can be used to study steel as it facilities the observation of chemical attack at defined anodic region and chloride addition guaranteed the effective attack. The weight of the work electrode $(\mathrm{Ew})$ for all test was around $55.847 \mathrm{~g}$. $\mathrm{mol}^{-1}$ taking into account the Fe (pure) as reference since this material $(\mathrm{Fe})$ present low carbon content.

To evaluate the erosive phenomenon, it was applied cathodic protection of $1 \mathrm{~V}$ cathode with respect to the open circuit potential of samples of the austenitic alloys, according to the ASTM G $119-93^{[19]}$ standards. This cathodic protection, assures surface damage only by effect of the erosive particles. The specimens were subjected to wear by erosion for a total exposure time of 240 minutes (time of the Tafel tests) at a temperature of $25^{\circ} \mathrm{C}$. In order to determine the weight loss due to the erosion during the immersion in $\mathrm{NaCl} 0.5 \mathrm{M}$ and Silica particles, the samples were removed from the solution at intervals of 15 minutes, they was cleaned with a jet of water, dried with a hot air, and evaluated on a balance to the nearest $0.1 \mathrm{mg}$. Finally, the process of surface corrosion was analyzed and the superficial morphology was characterized by using a High-Resolution Scanning Electron Microscope (SEM) (Philips XL 30 FEG).

\section{Results and Discussion}

\subsection{Dynamic corrosion}

Figure 1 shows the effect of the changes in the electrochemical system on the behaviour of the material with respect to the different regions of the polarization curve. First, it is possible to differentiate the action of the corrosive environment from the predominant type of polarization that occurs in each steel, because it provides an approximation to the type of surface mechanism that acts in each case, in marine environment it is observed from the anodic branch a species of charge transfer polarization, therefore, once it through the potential barrier, it will start the corrosion process of generalized type.

Table 1. Chemical composition of alloys.

\begin{tabular}{ccccc}
\hline Element & $(\mathbf{A ~ F e})$ & $\mathbf{( A ~ F e})$ & $(\mathbf{A ~ F e})$ & (A Inox) \\
\hline $\mathrm{Ni}$ & 0.039 & 0.022 & 0.026 & 12.0 \\
$\mathrm{Al}$ & 4.9 & 6.13 & 11.0 & -- \\
$\mathrm{Mn}$ & 17.49 & 28.21 & 34.3 & 2.0 \\
$\mathrm{C}$ & 0.43 & 0.49 & 1.25 & 0.08 \\
$\mathrm{Cr}$ & 6.68 & 6.17 & 6.69 & 17.0 \\
$\mathrm{Si}$ & 0.079 & 0.412 & 0.538 & 1.0 \\
$\mathrm{Mo}$ & 0.045 & 0.045 & 1.096 & 2.5 \\
$\mathrm{P}$ & 0.019 & 0.020 & 0.046 & -- \\
$\mathrm{Nb}$ & 0.005 & 0.0041 & 0.097 & -- \\
$\mathrm{V}$ & 0.009 & 0.028 & 0.073 & -- \\
$\mathrm{Sn}$ & 0.015 & 0.014 & 0.021 & -- \\
$\mathrm{Fe}$ & Balance & Balance & Balance & Balance \\
\hline
\end{tabular}


From this study, it was obtained that the $316 \mathrm{~L}$ stainless steel, shows a large displacement to lower corrosion current densities indicating lower susceptibility to the corrosion in the analyzed solution. This behavior can be attributed to the protection degree that generates this type of material, which may generate higher resistance path for the passage of the $\mathrm{Cl}$ ion, an analogue behavior is observed for the AF1 alloy, because its values are similar in density and corrosion speed are equivalent to the A Inox specimen. The displacement of the Tafel curves to the negative potential, decreases as the main alloying elements (Mo, Mn, Al, Cr), lies in the nature of the protective layer (passive layer), which act as scattering points, making difficult the migration of the $\mathrm{Cl}$ ion from the surface to the metal substrate and delay the onset of the corrosive processes ${ }^{8}$.

This leads to the required energy of the ions of the solution to migrate freely from the surface to passive interface layer/substrate. This is higher with the increase in the elements of molybdenum, aluminum and chromium, in the case of the molybdenum, its positive effect is associated with stabilizing the passive film and/or the formation of molybdates and molybdenum oxides, which is reflected in the decrease in corrosion current density and the corrosion rate (Table 2) ${ }^{9}$. Then, under such circumstances, it is appropriate to say that the AFe1 fermanal steel is a material with an electrochemical behavior very similar to the behavior presented by the $316 \mathrm{~L}$ stainless steel, which can be attributed to the alloying effect of the material with Mo.

\subsection{Erosion}

Figure 2 evaluates the loss of material associated with repeated impacts of solid particles after 240 minutes of test for two types of alloys. It differs clearly the wear severity with respect to the variation of the alloy fermanal in the normal angle condition. This type of wear is the result of successive impact of abrasive particles with a maximum linear velocity of $11.12 \mathrm{~m} / \mathrm{s}$ on the surface of the material. In the erosion weathering is generated a phenomenon of transfer energy where the kinetic energy of the particle is involved with a maximum of $5.466 \mathrm{~mJ}$, over the entire surface, in shock action on a metal surface that responds absorbing this amount of energy in terms of their resilience and toughness is possible to understand how the stainless steel is not affected to a greater extent by such attack. In this condition, it shows that erosion losses in the AFe 2 fermanal steel reduce with respect to the $\mathrm{AFe} 3$ steel taking into account the trend shown in normal angle where the dynamic curves of wear had very close values; this effect presume that the fermanal steel alloyed with $\mathrm{Si}, \mathrm{Nb}$ and $\mathrm{V}$ (transition elements), are strong carbides formers. These these elements are added to the fermanal alloys in order to reduce the detrimental effect of the chromium carbide precipitation and the subsequent sensitization to the intergranular corrosion and surface hardening increase. In the case of the AFe1 steel, it can clearly determine that the wear kinetic is analog to that shown by the stainless steel, which allows to set up to this fermanal steel, alloyed with molybdenum as a tough enough material for similar applications to those simulated in the rotary cylinder configuration in a normal angle under a entire wear mechanism despite that the failure mechanism in these cases is due to the cracking of the surface because the impact force of the particles is normally applied delivering to the surface all the kinetic energy.

\subsection{Corrosion erosion}

In relation with the anodic polarization curves in Figure 3 , it shows the erosion-corrosion synergy in the aggressive environment. The synergy is a major factor in

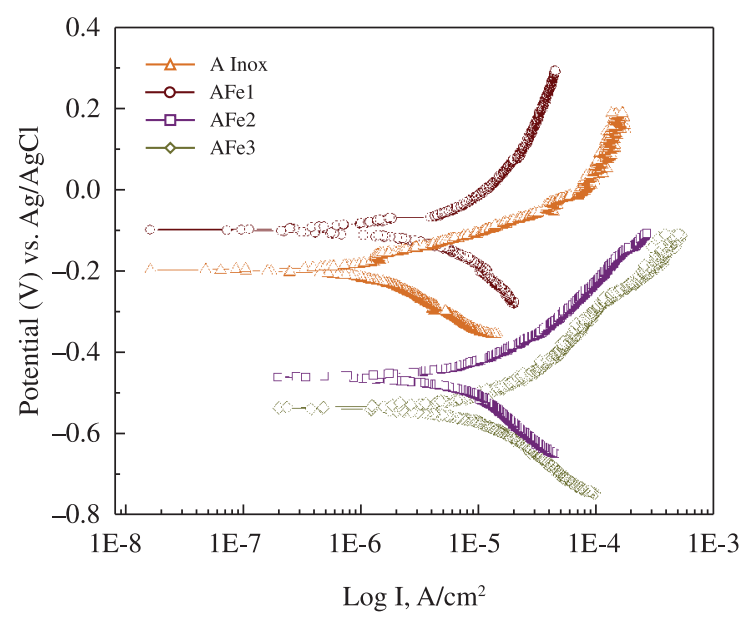

Figure 1. Anodic polarization curves of the corrosion behavior in dynamic and fermanal stainless steels in a solution of $0.5 \mathrm{M} \mathrm{NaCl}$.

Table 2. Values of electrochemical parameters for 316L stainless steel and fermanal steel, obtained from polarization curves in the dynamic corrosion system.

\begin{tabular}{cccc}
\hline Sample & $\begin{array}{c}\text { Corrosion } \\
\text { potential }(\mathbf{m V})\end{array}$ & $\begin{array}{c}\text { Corrosion current } \\
\left(\boldsymbol{\mu} \mathbf{A . c m} \mathbf{c m}^{-2}\right)\end{array}$ & $\begin{array}{c}\text { Corrosion } \\
\text { rate }(\boldsymbol{\mu m y})\end{array}$ \\
\hline $\begin{array}{c}\text { Stainless } \\
\text { steel }\end{array}$ & -196 & 2.33 & 1.54 \\
$\mathrm{~A} \mathrm{Fe} 1$ & -98 & 5.08 & 3.30 \\
$\mathrm{~A} \mathrm{Fe} 2$ & -462 & 9.63 & 6.34 \\
$\mathrm{~A} \mathrm{Fe} 3$ & -535 & 14.72 & 9.64 \\
\hline
\end{tabular}

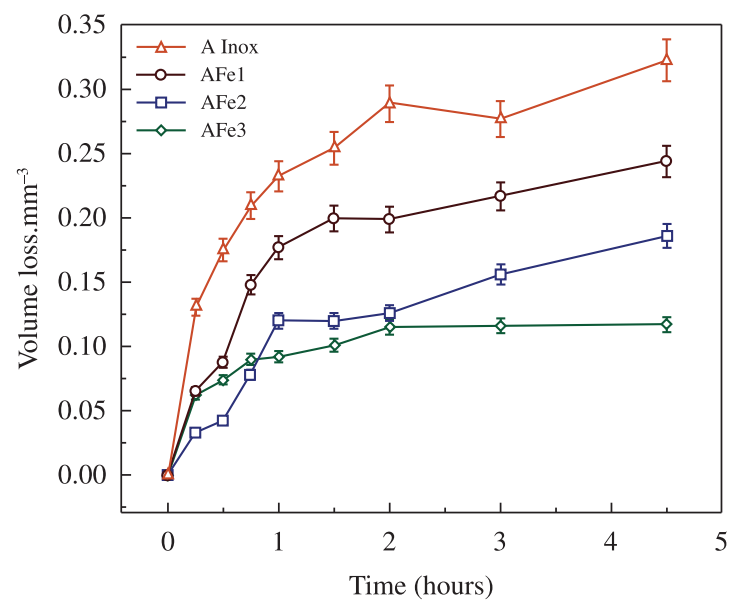

Figure 2. Volume loss for stainless and fermanal steel without corrosive effect. 
the severity of induced mechanical wear. It implies that the phenomenon could become additive. It means, that the corrosive electrochemical phenomenon would be the dominant in the marine environment. This aggressive effect of the environment is attributable to the action of the chloride ion which promotes further corrosion pitting on the material surface to propagate by the incessant impact of the particles ranging in size from $210 \mu \mathrm{m}$ and $300 \mu \mathrm{m}$ causing the release of the material in the non passivated areas, transfer in the hardened layers of the surface. This phenomenon is more evident in $\mathrm{AFe} 2$ and $\mathrm{AFe} 3$ materials. In general and as expected, the materials under study have an increase in the activity, especially of the corrosion current density when it is subjected to an environment under dynamic conditions in particular under the action of erosive particles. It is observed that the modification of the mechanical condition of the environment, such as the fluid impact and the erosive particles at certain attack angles, leading to a slight change of corrosion potential for the AFe1 steel, because the effect of the agitation of the environment by the dissipation of energy in it, while at the same time it shows an increase in the corrosion current density effect of the particles attack and the subsequent generation of widespread corrosion points. It should be mentioned that stainless steel in notable for its very stable corrosion potentials as environmental conditions change, it is an effect that is not apparent in fermanal alloys, which show an evident thermodynamic increased of the activity in the dynamic environments, not however, AFe1 fermanal steel generates a density and corrosion rate in narrow ranges similar to those shown by the stainless steel which is an important aspect in engineering applications where the changing environmental conditions of work require that the material is sufficiently stable thermodynamically to compensate these changes without incurring in loss of resistant area of the material which is closely related to the applied stress.

The data shown in Table 3 indicate a low electrochemical performance to the dynamic corrosion (Table 2), due to the erosion-corrosion generates decrease in the potential and corrosion density. Figure 3 indicate that the metal is removed from the surface because the silica abrasive particles generate a type of wear that subsequently removes some of the material due to corrosive effect in ionic form or as solid corrosion products. In general, the data (Table 3 ) show a good performance of all the studied steels in comparison to stainless steel when those are subjected to corrosive phenomena. Nevertheless, when these steels are subjected to corrosive-erosive flow, the passive film formed usually on the surface is eliminated and removed by the action of hard particles, leading to loss of corrosion protection. The corrosion for its part reduces the resistance of these steels on the surface for the attack of the particles thus favoring the increase in corrosion rate compared to the dynamics corrosion (Figure 1).

\subsection{SEM observation of tested specimens}

Figure 4 shows the SEM micrographs of the surface characteristics of fermanal and 316L stainless steels then to the process of erosion corrosion impact angles of $90^{\circ}$. According to Figure 4a, b, part of the specimens has been damaged by the dynamic corrosion effect. Additionally, the coating cracking wear is displayed. Figure $4 c, d$, it is distinguished a central area characterized by the corrosion action and the cracking of the coating produced by the impact energy of the abrasive particles of silica. Gray areas suggest protective effect has generated defense mechanism with areas of low cracking. By subjecting the surface of the fermanal steels and stainless steels to erosion-corrosion it is notable the modification of the surface for an impact angle of $90^{\circ}$ degrees showing faint traces on surface of material. Figure $4 \mathrm{~b}$ shows the micrographs by formation of localized corrosion which begins to spread over much of the surface. In this case, the eroded surface is very similar to those shown over stainless steel. For AFe2 steel under the action of the marine environment can be seen that the steel surface show areas of generalized corrosion, which has spread across most of the surface, while being subjected the surface to the erosion it is observed a significant damage in the normal angle condition, causing a rough morphology. Both mechanism in synergy, are responsible for a surface with an evident deterioration of material, as in the case of $90^{\circ}$ degrees angle where there are traces of mechanical removal of material. The AFe 3 steel shows a bigger erosive phenomenon than in the previous cases, it is reflected in a rough surface and slightly texture in the direction of impact of the particles. Also are observing a surface with clear

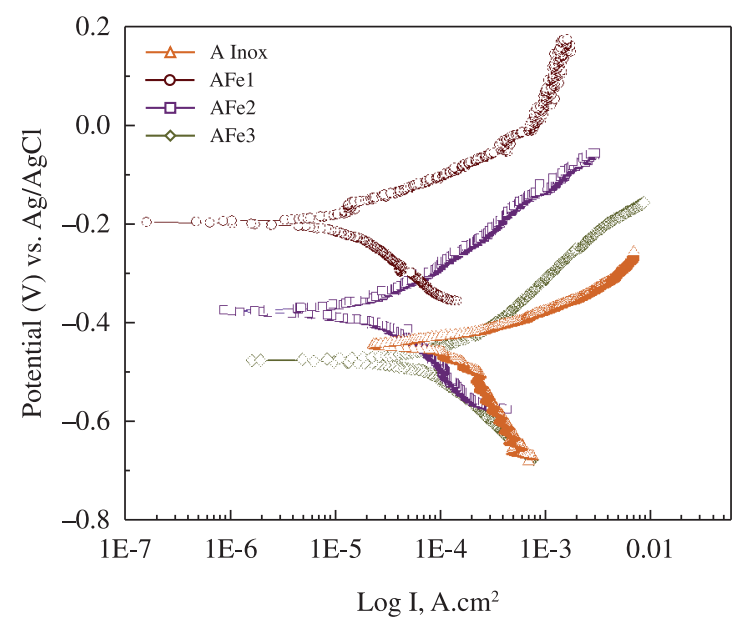

Figure 3. Anodic polarization curves of stainless and fermanal steels corresponding to the erosion corrosion effect in a solution of $\mathrm{NaCl} 0.5 \mathrm{M}$.

Table 3. Values of electrochemical parameters for 316L stainless steel and fermanal steel, obtained from polarization curves in the erosion corrosion system.

\begin{tabular}{cccc}
\hline Sample & $\begin{array}{c}\text { Corrosion potential } \\
(\mathbf{m V} \text { vs Ag/AgCl) }\end{array}$ & $\begin{array}{c}\text { Corrosion } \\
\text { current }\left(\boldsymbol{\mu A . \mathbf { c m } ^ { - 2 } )}\right)\end{array}$ & $\begin{array}{c}\text { Corrosion } \\
\text { rate }(\boldsymbol{\mu m y})\end{array}$ \\
\hline $\begin{array}{c}\text { Stainless } \\
\text { steel }\end{array}$ & -198 & 18 & 11.14 \\
A Fe1 & -376 & 29 & 19.16 \\
A Fe2 & -440 & 106 & 66.34 \\
A Fe3 & -481 & 186 & 122.94 \\
\hline
\end{tabular}




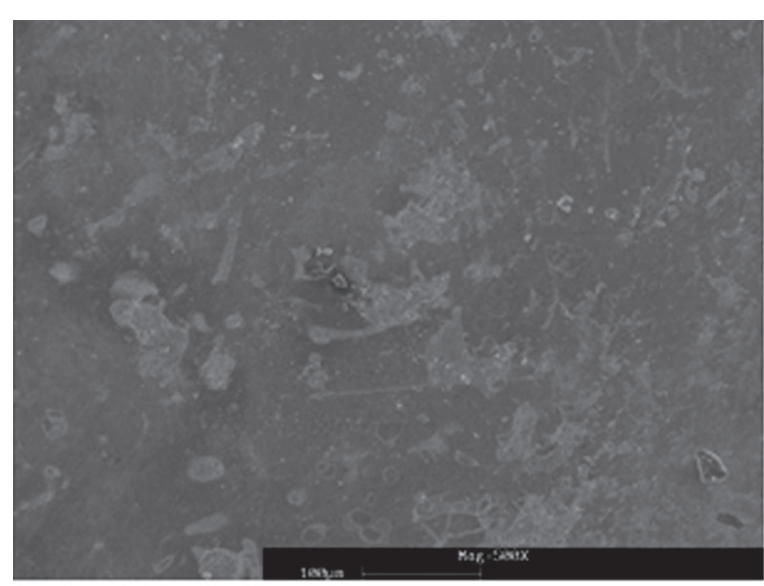

(a)

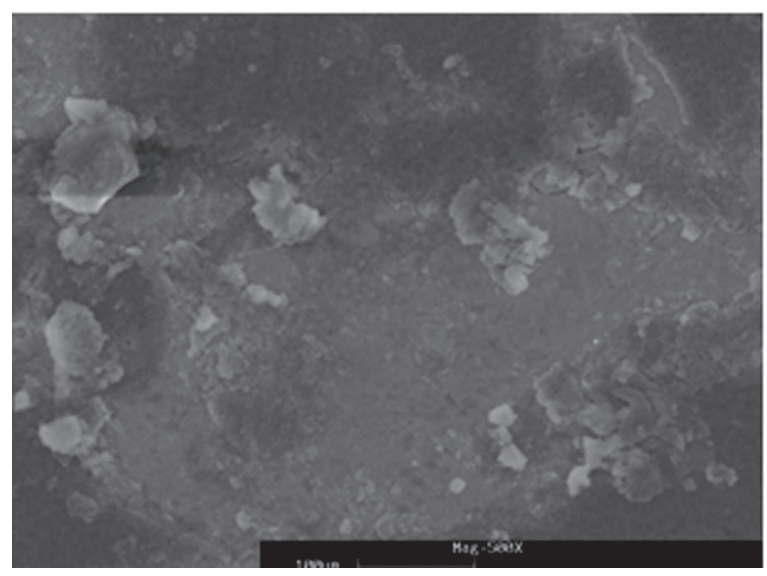

(c)

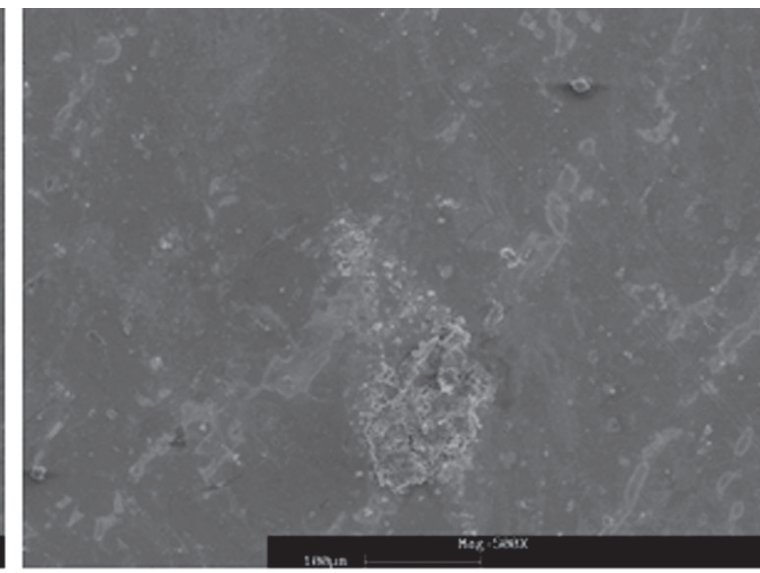

(b)

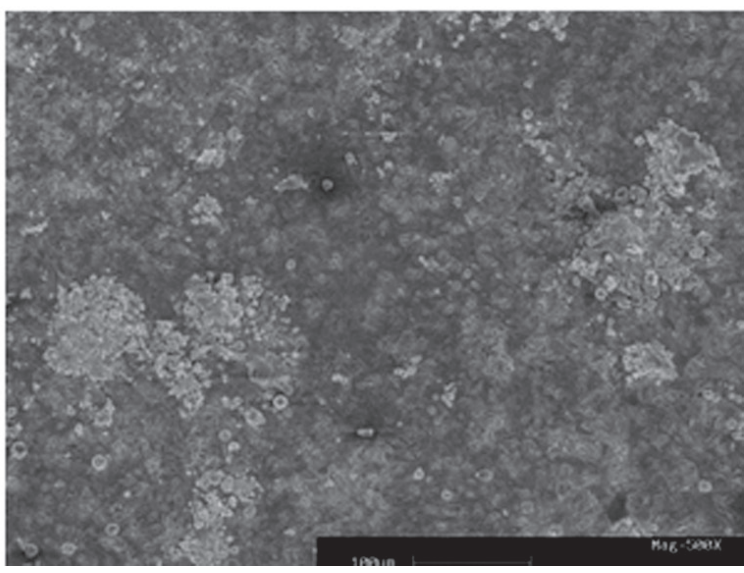

(d)

Figure 4. SEM micrographs for samples subjected to corrosion-erosion. a) 316L stainless steel; b) AFe1 Fermanal; c) AFe2 Fermanal; d) AFe3 Fermanal.

signs of mechanical wear with, deeper traces and greater surface roughness.

SEM micrographs shows the AFe3 and AFe2 fermanal steel have formation primary oxides in to the lower proportion that fermanal AFe1 steel. The high losses are due to the erosion-corrosion of this material in the marine environment, generated an unstable oxide film, owing to a low coefficient passivation the Manganese. Similarly, we observe that the action of the environment has led to the formation of some $\mathrm{Mn}-\mathrm{Fe}$ and $\mathrm{Fe}-\mathrm{Al}$ spinels, which due to its compact and stable structure can generate surface protection to the phenomenon of electrochemical deterioration when it is combined with the erosive phenomenon.

\section{Conclusions}

The results of the potentiodynamic anodic curves show that the austenitic stainless steel and AFe1 alloys have an excellent electrochemical behaviour and for the AFe 2 and
AFe3 steels is good in conditions of dynamic corrosion. Under condition of normal attack angle, it is observed that the steel samples $\mathrm{AFe} 2$ and $\mathrm{AFe} 3$ are more active while $\mathrm{AFe} 1$ steel samples have a noble behavior. For the types of steels evaluated is deduced an anodic behavior represented by a continuous anodic dissolution phenomenon.

In this work, it was noted that the decrease in wear rate is in relationship to an enhancement in the mechanical properties generated by the absorption and distribution of the impact. In the mechanism of synergy of erosion corrosion showed that the AFe 3 and $\mathrm{AFe} 3$ steels have increased activity, especially the corrosion current density when they are subjected to dynamic conditions in particular and additionally to the action of erosive particles.

\section{Acknowledgements}

This research was supported by "Universidad Militar Nueva Granada" (UMNG). 


\section{References}

1. Dunning JS, Alman DE and Rawers JC. Influence of silicon and aluminium additions on the oxidation resistance of a leanchromium stainless steel. Oxidation of Metals. 2002; 57:409-425. http://dx.doi.org/10.1023\%2FA\%3A1015344220073

2. Lins VF. Freitas MA and Paula e Silva EM.Corrosion resistance study of Fe-Mn-Al-C alloys using immersion and potentiostatic tests. Applied Surface Science. 2005; 250(1-4):124-134. http:// dx.doi.org/10.1016\%2Fj.apsusc.2004.12.040

3. Trindade VB, Krupp U, Zandi HB, Yang S and Christ HJ. Effect of alloy grain size on the high-temperature oxidation behavior of the austenitic steel TP 347. Materials Research. 2005; 8(4):371-375. http://dx.doi.org/10.1590\%2 FS1516-14392005000400003

4. Zhang YS, Lu X, Tian X and Qin Z. Compositional dependence of the Néel transition, structural stability, magnetic properties and electrical resistivity in $\mathrm{Fe}-\mathrm{Mn}-\mathrm{Al}-\mathrm{Cr}-\mathrm{Si}$ alloys. Materials Science and Engineering. 2002; 334(1-2):19-27. http://dx.doi. org/10.1016\%2FS0921-5093\%2801\%2901781-6

5. Wang $\mathrm{CJ}$ and Chang $\mathrm{YC}$. NaCl-induced hot corrosion of $\mathrm{Fe}-\mathrm{Mn}-\mathrm{Al}-\mathrm{C}$ alloys. Materials Chemistry and Physics. 2002; 76(2):151-161. http://dx.doi.org/10.1016\%2 FS0254-0584\%2801\%2900515-6

6. Binczyk F, Smolinski A and Szymszal J. The heat treatment of Fermanal cast steel. Archives of Foundry Engineering. 2007; 7(4):9-12.

7. Białoń J, Dudek D, Kobylańska-Szkaradek K and Zastawny A.The influence of nuclear Radiation on some physical properties of fermanal steel. Materials Science and Engineering. 1983; 59(2):217-222. http://dx.doi.org/10.101 6\%2F0025-5416\%2883\%2990169-6

8. Aperador W, Vargas A and Betancur J. Respuesta electroquímica de aleaciones fermanal. expand. ed. Académica Española; 2011.

9. Ivanova S, Litvak G, Mokrinskii V, Plyasova L, Zaikovskii V, Kaichev $\mathrm{V}$ et al. The influence of the active component and support nature, gas mixture composition on physicochemical and catalytic properties of catalysts for soot oxidation. Journal of Molecular Catalysis A: Chemical. 2009; 310(1-2):101-112. http://dx.doi.org/10.1016\%2Fj.molcata.2009.06.004
10. Vargas A, Aperador W, Ortiz C, Betancur J and Wang C. Caracterización electroquímica de fermanal expuesto a condiciones corrosivas-erosivas. Revista Latinoamericana de Metalurgia y Materiales. 2009; 1(S1):149-155.

11. Zhang YS, Zhu XM and Zhong SH. Effect of alloying elements on the electrochemical polarization behavior and passive film of $\mathrm{Fe}-\mathrm{Mn}$ base alloys in various aqueous solutions. Corrosion Science, 2004; 46(4):853-876. http://dx.doi.org/10.1016\%2Fj. corsci.2003.09.002

12. Zhang YS, Zhu XM, Liu M, Che RX. Effects of anodic passivation on the constitution, stability and resistance to corrosion of passive film formed on an Fe-24Mn-4Al-5Cr alloy. Applied Surface Science. 2004; 222(1-4):89-101. http:// dx.doi.org/10.1016\%2Fj.apsusc.2003.08.068

13. Huang H-H and Chuang T-H. Erosion- and wear-corrosion behavior of $\mathrm{Fe}-\mathrm{Mn}-\mathrm{Al}$ alloys in $\mathrm{NaCl}$ solution. Materials Science and Engineering: A. 2000; 292(1):90-95. http://dx.doi. org/10.1016\%2FS0921-5093\%2800\%2901021-2

14. Holmberg K, Matthews A and Ronkainen H. Coatings Tribology- contact mechanisms and surface design. Tribology International. 1998; 31(1-3):107-120. http://dx.doi. org/10.1016\%2FS0301-679X\%2898\%2900013-9

15. Bautista J, Aperador $\mathrm{W}$ and España C. Desgaste abrasivo y corrosivo de recubrimientos TiN/TiAlN y TiN/AlTiN. expand. ed. Académica Española; 2011.

16. Caicedo JC, Amaya C, Yate L, Aperador W, Gómez ME and Prieto P. Improvement of the electrochemical behavior of aisi 4140 steel substrate using [TICN/TINBCN]N multilayers system. In: Wong TM. Niobium: Properties, Production and Applications. Nova Science Publishers Inc; 2011. p. 167-178.

17. American Society for Testing and Materials - ASTM. ASTM G5-94: Standard Reference: Test Method for Making Potentiostatic and Potentiodynamic Anodic Polarization Measurements. West Conshohocken: ASTM; 2004.

18. American Society for Testing and Materials - ASTM. ASTM G99-97: Standard Test Method for Conducting Potentiodynamic Polarization Resistance Measurements. West Conshohocken: ASTM; 2009.

19. American Society for Testing and Materials - ASTM. ASTM G119-09: Standard Guide for Determining Synergism Between Wear and Corrosion. West Conshohocken: ASTM; 2004. 